\title{
Vivir Bien e Soft Power: Análise da Política Externa do Estado Plurinacional da Bolívia
}

"Vivir Bien" and Soft Power: Analysis of the Plurinational State of Bolivia Foreign Policy

\author{
Lucas Duarte Guerra ${ }^{1}$
}

\section{RESUMO}

A partir de uma abordagem pluralista da política externa, esse artigo busca evidenciar que há relação entre a alteração na correlação de forças na arena nacional da Bolívia sob a gestão Morales e o novo modelo de inserção internacional pautado pelo país. Os conceitos de "Vivir Bien" e "Soft Power" são utilizados para demonstrar como elementos da política doméstica boliviana foram operacionalizados na estratégia de política exterior do país.

Palavras-Chave: Política Externa da Bolívia; Vivir Bien; Soft Power.

\begin{abstract}
From a pluralistic approach of the Foreign Policy Analysis, this article aims to evidence that there is a relation between the change in the correlation of forces in the national arena of Bolivia under the Morales administration and the new international insertion model adopted by the country. The concepts of "Vivir Bien" and Soft Power are used to demonstrate how elements of the Bolivian domestic policy have been operationalized on the country's foreign policy strategies.
\end{abstract}

Key-Words: Bolivian Foreign Policy; Vivir Bien; Soft Power.

\section{INTRODUÇÃO}

A gestão do Presidente Evo Morales, iniciada no ano de 2006, resultou na conformação de uma nova conjuntura política na Bolívia, marcada por nova hegemonia partidária, empoderamento de grupos sociais antes marginalizados (com ênfase para os indígenas) e pela própria "refundação" do Estado sob a condição de Plurinacional, com a aprovação da nova constituição do país por referendo popular no ano de 2009. Partindo de uma perspectiva pluralista da política externa, esse artigo busca responder se há relação entre a nova correlação de forças e transformações políticas em curso na arena

1 Graduando em Relações Internacionais e Integração, UNILA, Foz do Iguaçu, Brasil. 
doméstica da Bolívia e a estratégia de inserção internacional pautada na política externa do país.

Para tanto, o artigo se encontra organizado em três partes. A primeira traz uma apresentação dos conceitos centrais utilizados na análise proposta, com especial atenção para os de Vivir Bien e Soft Power, respectivamente essenciais para a compreensão das mudanças em curso no Estado boliviano sob a condição de Plurinacional e da relação entre os processos internos experimentados pela Bolívia e o novo modelo de inserção internacional recentemente adotado pelo país. A segunda parte se dedica a uma breve contextualização histórica das mudanças políticas empreendidas na Bolívia, apontando também alguns dos resultados dessas mudanças na arena doméstica do país. Por fim, a terceira parte aborda as transformações na política externa da Bolívia decorrente desses processos, seguida de breves considerações finais acerca dos resultados obtidos.

\section{Marco Teórico-Conceitual}

Para uma melhor compreensão a respeito da discussão que se pretende desenvolver nesse artigo, primeiramente se faz necessária uma conceptualização quanto ao marco teórico e termos centrais que serão operacionalizados na composição da argumentação ao longo do texto, sendo eles Política Externa, Soft Power e Vivir Bien.

Em primeiro lugar, a perspectiva de política externa adotada transcende as abordagens tradicionalistas, que concebem o Estado como ente unitário e dotado de razão própria em sua atuação no exterior. Nessa concepção, o "interesse nacional" é definido em termos de sobrevivência em um Sistema Internacional anárquico, parte da própria Ragion di Stato, de modo que atores e processos da arena política doméstica dos Estados não influenciam nem são levados em consideração nas análises de política exterior (FIGUEIRA, 2011; LOPES, 2012; SARFATI, 2005).

Em contraposição, a concepção de política externa adotada nesse texto é pluralista, reconhecendo a importância das dinâmicas, transformações, processos e atores domésticos na conformação das diretrizes e ações em política exterior. A ideia é representada pela metáfora de abrir a "caixa-preta" do Estado, buscando desvendar relações políticas e sociais, correlações de força, grupos de interesse, características das 
instituições e peculiaridades dos processos decisórios que possam influenciar na tomada de decisão (FIGUEIRA, 2011). Trata-se da consideração do caráter "interméstico" da política externa, compreendida como

resultante da interação entre as arenas doméstica e internacional, ou seja, as preferências dos países manifestas nas negociações internacionais não apenas consideram a interação com as demais unidades do sistema internacional, as possibilidades e os constrangimentos que estas oferecem, mas também as preferências manifestas internamente, sendo estas conjugadas por diversos atores e estruturas (Figueira, 2011, p. 24).

Conforme mencionado, a abordagem tradicionalista - representada pelas diversas vertentes da teoria Realista das Relações Internacionais - afirma que a busca pela sobrevivência orienta a atuação dos Estados no Sistema Internacional. A sobrevivência, por sua vez, está diretamente relacionada à quantidade de poder possuída pelos Estados, ou seja, a sua capacidade de influenciar ou controlar diretamente as ações de seus pares (MINGST, 2009). Portanto, de maneira geral, a política externa dos Estados estaria sempre direcionada ao aumento ou manutenção da quantidade de poder possuída no Sistema Internacional. Ainda de acordo com o paradigma realista, a melhor maneira de exercer o poder seria por meio da coerção, utilizando recursos tangíveis como embargos econômicos e, principalmente, a guerra (SARFATI, 2005).

Embora esse tenha sido o paradigma predominante nas análises das Relações Internacionais entre o início da II Guerra Mundial e parte da Guerra Fria, a partir da década de 1970 novos eventos em curso no cenário internacional colocaram em cheque alguns de seus preceitos fundamentais. $\mathrm{O}$ aumento da atuação de Organizações NãoGovernamentais Internacionais, abertura de espaço para novos temas - direitos humanos, meio ambiente, integração regional, etc. - na agenda internacional e as Crises do Petróleo, que evidenciaram a importância de elementos não militares nas relações de poder entre Estados, são alguns dos principais exemplos desse processo (SARFATI, 2005).

Nesse contexto, desenvolveu-se a teoria neoliberal das Relações Internacionais, sendo um de seus principais expoentes o autor estadunidense Joseph Nye. Buscando compreender como se daria o exercício de poder entre Estados nessa nova conformação da realidade internacional - marcada pela interdependência complexa entre nações e consequente alto custo político e econômico no emprego de recursos coercitivos -, o autor propõe o conceito de Soft Power. O "poder brando", em termos gerais, promoveria o 
exercício do poder através da cooptação, utilizando, para isso, o potencial atrativo de recursos imateriais do Estado, tais como cultura, valores, ideologias, lideranças carismáticas, diplomacia e mesmo políticas públicas domésticas bem-sucedidas (NYE, 2004).

Assim, um Estado que represente aspectos culturais consonantes com princípios e valores tidos como universais, que consiga materializar esses valores através de políticas públicas bem-sucedidas em âmbito nacional e internacional e cuja política externa reflita esses processos e seja respeitosa ao Direito Internacional, obterá credibilidade e autoridade moral - e, portanto, poder de atração - no cenário internacional (NYE, 2004). Através do uso do Soft Power, mesmo países com pouco poder militar ou econômico têm a capacidade de exercer prestígio e influência na política internacional.

Por fim, um conceito fundamental aos estudos que envolvem processos políticos, sociais e jurídicos na Bolívia contemporânea é o de Vivir Bien. Eixo estruturante de parte dos Novo Constitucionalismo latino-americano do século XXI, o Buen Vivir ${ }^{2}$ ou Vivir Bien representa a refundação do Estado sob uma nova configuração, pautada na ampliação da democracia, emancipação dos povos e concepção coletiva dos direitos básicos - incluindo questões de representatividade, identidades e acesso aos recursos naturais (BURCKHART, 2013).

De maneira geral, pode-se apontar três principais características do Vivir Bien enquanto ideia-força das novas Constituições que tem tomado forma na América Latina, cujos expoentes até o momento são a Bolívia e o Equador. A primeira, basilar para as demais, é a retomada da cosmovisão dos povos originários andinos enquanto norteadora dos princípios constitucionais. A partir desse processo, busca-se a construção de um modelo de desenvolvimento com base na plena realização dos potenciais humanos, na proteção da Natureza e na relação harmoniosa das pessoas entre si e destas com o meio que as cerca (HERNÁNDEZ, 2009). A garantia das necessidades básicas para a sobrevivência, combate contra todas as formas de violência (física, cultural ou estrutural) e defesa da liberdade política, de expressão e de pleno exercício da identidade tornam-se funções primordiais do Estado (TORTOSA, 2009).

A segunda característica é o caráter contestador aos padrões comportamentais e

2 Como é chamado no Equador, primeiro país a incluir a cosmovisão indígena como norteadora dos princípios constitucionais (Constituição de Montecristi, 2008). 
ideologias hegemônicas do Ocidente. O Vivir Bien se coloca como alternativa ao "Mal Vivir", modelo cuja representação máxima é o american way of life, que baseia sua noção de desenvolvimento no capital e no consumo (TORTOSA, 2008). A doutrina neoliberal, a subserviência política e econômica às grandes potências e as instituições de governança global também são fortemente criticadas, e a busca pela construção de espaços antihegemônicos alternativos é encorajada como princípio de política exterior (ACOSTA, 2008).

Por fim, o Vivir Bien promove a desconstrução parcial do Estado-Nação, visto como instrumento de legitimação da "colonialidade do poder" - baseada principalmente na ideia de superioridade racial branca sobre a vasta diversidade étnica presente na América Latina (QUIJANO, 2005). Em contraposição, promove a plena autonomia e representatividade jurídica e política dos diversos povos indígenas no interior do Estado, processo que na Bolívia se traduziu na formação de um Estado "Plurinacional".

\section{Bolívia: dos Impactos do Neoliberalismo à fundação do Estado Plurinacional}

De maneira semelhante aos demais países da América Latina, a década de 1980 na Bolívia foi marcada pela redemocratização pós-ditadura e busca por um novo modelo de inserção internacional em uma realidade marcada pela consolidação definitiva da globalização econômica (LIMA, 2000). Nesse sentido, a região passou por uma forte guinada rumo ao modelo neoliberal, adotando os princípios promulgados pelo Consenso de Washington de liberalização comercial, privatização das empresas nacionais, mínima intervenção estatal na economia e cortes nos investimentos sociais (MENEZES, 2007).

Na Bolívia, o desenvolvimento do neoliberalismo ao longo de quase duas décadas levou à privatização das principais empresas mineradoras nacionais e das reservas de hidrocarbonetos no subsolo do país, acarretando também na desestabilização das principais entidades trabalhistas e de luta social bolivianas (GOMES E SOUZA, 2009). 0 avanço das privatizações chegou ao nível de atingir a gestão do fornecimento de água à população, concedido a uma filial da corporação estadunidense Brechtel Corporation. Tal evento, ocorrido em 2000, serviu como estopim da insatisfação popular, conduzindo à rearticulação dos movimentos sociais bolivianos e organização de protestos nas ruas das 
principais cidades do país, processo que ficou conhecido como “Guerra da Água” (ARZE, 2004).

Apesar da forte repressão estatal, a demanda popular por revogação dos contratos de privatização da água foi atendida. A articulação dos movimentos sociais na luta contra as ofensivas do neoliberalismo, porém, não cessou. Em 2003, eclodiu a chamada “Guerra do Gás", na qual as ruas foram novamente tomadas por movimentos em luta contra a discrepância entre os altos lucros obtidos pelas empresas estrangeiras extratoras de gás e as péssimas condições de vida da população. Entre as exigências populares, estavam a renacionalização dos hidrocarbonetos e a renúncia do então Presidente, Gonzalo Sánchez de Lozada (ARZE, 2004). Lozada renunciou ao cargo, assim como seu vice-presidente e os dois nomes seguintes na linha de sucessão presidencial, sendo esse o ápice de um longo período de grave instabilidade política, social e econômica no país.

É frente a esse contexto que surge a figura de Evo Morales, ativista político com forte atuação nos protestos populares antineoliberais e líder do movimento cocalero boliviano. A proximidade com os movimentos sociais e discurso pró nacionalização dos recursos nacionais do país concederam forte apoio popular a Evo, que em 2006 tomou posse como primeiro Presidente indígena na História da Bolívia, eleito com 53,7\% dos votos - maioria inédita no período pós-redemocratização do país (FERNÁNDEZ, 2009).

Evo candidatou-se à Presidência pelo partido que ajudou a fundar, o Movimiento al Socialismo (MAS), composto por movimentos sociais campesinos, indígenas e sindicais, criado na década de 90, com o objetivo de consistir em instrumento político de representação democrática no combate às políticas neoliberais (ZUAZO, 2010). Em 2006, além do Presidente, foram eleitos 84 congressistas do MAS, de um total dos então 157 membros da Assembleia Geral do país ${ }^{3}$. O PODEMOS, principal partido de oposição, contava com apenas 54 cadeiras.

Ademais, conforme mencionado, a ascensão de Evo Morales e do MAS ao poder contou com amplo apoio das camadas populares e movimentos sociais, possibilitando a formação de um bloco de consenso e estabilidade política inédito no período contemporâneo da História do país. Assim, se solidificou a construção de uma nova correlação de forças na arena doméstica boliviana. Grupos ligados à agroexportação e

3 Fonte: Corte Nacional Electoral de Bolivia. 
agroindústria, mantenedores de relações carnais com o capital internacional e beneficiários dos moldes neoliberais, perderam a hegemonia política no país. No lugar da ideologia e padrão de organização política, social e econômica pregados por estes, uma série de novos princípios foram materializados na concepção da atividade estatal na Bolívia. 0 principal resultado desse processo traduz-se no ordenamento proposto pela Constituição do Estado Plurinacional da Bolívia, ratificada em referendo popular e passando a entrar em vigor no ano de 2009.

A Nova Constituição da Bolívia é edificada sobre os ideais do Vivir Bien, e propõe a refundação do Estado a partir de um novo conjunto de princípios e valores, promovendo uma série de transformações. A principal delas é a ruptura com o conceito de EstadoNação, propondo em seu lugar o Estado Plurinacional e comunitário. Sob esse marco, confere-se plena autonomia e emancipação jurídica e política às comunidades indígenas em território boliviano e a oficialização dos 36 idiomas indígenas falados na Bolívia, medidas essenciais para o empoderamento da outrora excluída e marginalizada população indígena do país (aproximadamente 62,2\% da população4).

Outra mudança de grande importância diz respeito aos recursos naturais da Bolívia. De acordo com a Nova Constituição, todos os recursos em território boliviano pertencem ao povo, cabendo ao Estado sua administração. Essa cláusula conferiu legitimidade jurídica à nacionalização dos hidrocarbonetos empreendida no governo Morales, política considerada a "base material de um Estado plurinacional" (TAIPA, 2007, p. 59), conferindo ao Estado o capital necessário para a sua atuação na esfera social.

\footnotetext{
Com a nacionalização, obrigaram-se as empresas transnacionais a firmar novos contratos e o Estado passou a determinar os volumes e preços de exportação, além de retomar o controle de toda a cadeia produtiva através da refundação da estatal Yacimientos Petrolíferos Fiscales Bolivianos (YPFB) e da nacionalização de refinarias e gasodutos. Isso tudo contribuiu para que o governo conseguisse um superávit fiscal, num contexto de altos preços internacionais de matériasprimas, recursos com os quais se financiam, como mencionado, as políticas sociais." (Stefanoni, 2010, p. 123)
}

Com base nesse processo de democratização das rendas obtidas com a exportação de hidrocarbonetos, logrou-se na gestão Morales uma elevação do PIB per capita da

4 Fonte: Comissão Econômica para a América Latina, 2014.

Conjuntura Global, vol. 5 n. 1, jan./abr., 2016, p. 189-204. 
Bolívia de 2900 dólares anuais (2005) para 5.500 em 2013 ; do Índice de Desenvolvimento Humano de 0,647 (2005) para 0,675 (2012) ${ }^{6}$, além da manutenção de uma média de crescimento econômico anual de 5,3\% desde 2009, maior índice da América Latina7.

Conforme já se argumentou, a perspectiva analítica adotada nesse artigo considera dinâmicas e atores da arena doméstica dos Estados como elementos essenciais para a compreensão de sua política externa. Assim, a nova correlação de forças predominante na Bolívia, marcada pela hegemonia política do $M A S$, pelo empoderamento dos movimentos sociais indígenas, campesinos e cocaleros e pela inauguração de um novo ordenamento jurídico no país, repercutiu em uma série de transformações nas estratégias de inserção internacional da Bolívia. Estas se deram primeiramente em um período de atritos e dificuldades no processo de autoafirmação, seguido por um momento de busca por legitimidade e prestígio junto à comunidade internacional.

\section{A Política Externa do Estado Plurinacional da Bolívia}

A Constituição do Estado Plurinacional da Bolívia (2009) propriamente dita trouxe poucas alterações no processo decisório de política externa do país. Em linhas gerais, há continuidade de um modelo hiperpresidencialista (art.172-5), com participação legislativa no lugar de veto player (art. 158 - I). Ademais, a participação cidadã através de referendos é positivada em casos que envolvam questões limítrofes, de integração monetária e cessão de soberania a organismos supranacionais de integração (art. 257 II). Além desses casos específicos, qualquer tratado pode ser submetido a referendo caso assim solicitem $5 \%$ dos cidadãos cadastrados no sistema eleitoral do país ou $25 \%$ da Assembleia Legislativa Plurinacional (art. 259 - I).

Entre as diretrizes constitucionais para política externa (art. 255), estão o rechaço ao colonialismo, neocolonialismo e imperialismo; preservação da capacidade de gestão e regulação do Estado e proibição da apropriação privada dos recursos naturais do país.

$5 \quad$ Fonte: CIA World Factbook, consultado em dez. 2015.

6 Fonte: PNUD, consultado em dez. 2015.

$7 \quad$ Fonte: CIA World Factbook, consultado em dez. 2015. 
Concomitantemente a tais princípios, o Ministério das Relações Exteriores e Culto da Bolívia, liderado pelo ativista indígena David Choquehuanca, afirma em documento oficial que, frente ao contexto pós-neoliberal do país

\begin{abstract}
Se requería construir una nueva política exterior profundamente anclada en la diversidad cultural y la identidad plurinacional del pueblo boliviano; una política exterior que tuviera seriamente en cuenta la necesidad de defender de la voracidad de agentes externos los recursos naturales existentes en el país, en particular los considerados estratégicos, (...) una política exterior orientada a articular alianzas estratégicas que permitan incrementar la capacidad negociadora del país y mejorar sua inserción en el contexto internacional y su proyección geopolítica en la región; una política exterior que cuente con la participación de las instituciones públicas, los movimientos sociales y las organizaciones de los sectores majoritarios de la población en su formulación y ejecucíon (...) (p. 57).
\end{abstract}

Esses princípios, consonantes com as prerrogativas do Vivir Bien e com a nova correlação de forças consolidada na Bolívia com a ascensão de Evo Morales ao poder, refletem a afirmação do país contra os preceitos neoliberais e a hegemonia das grandes potências, concretizando-se em atuações externas que geraram um certo abalo nas relações da Bolívia com a comunidade internacional.

A primeira delas foi a ruptura das relações de tutelagem com os Estados Unidos da América. Em um momento inicial do governo Morales, o embaixador estadunidense na Bolívia foi expulso do país, acusado de intervenção em assuntos internos e conspiração política contra o Presidente. Além do rompimento de relações diplomáticas, houve um forte rechaço e desmantelamento da política estadunidense de "combate às drogas" denominada "Coca Zero".

Tal política, diretamente relacionada aos interesses de Washington em manter controle e forte ingerência na política interna dos países latino-americanos (SOUZA, 2010), consistia no combate ao narcotráfico de cocaína através da erradicação total da produção de folhas de coca, atividade tradicional e milenar dos povos indígenas e campesinos da região andina, violentamente reprimidos pelas incursões armadas da agência militar estadunidense Drug Enforcement Administration (DEA).

As medidas adotadas nesse sentido da erradicação do plantio de coca oscilavam entre a utilização da repressão física, através da atuação das Forças Armadas, uso de agentes químicos sobre as plantações do produto, o oferecimento de financiamentos e de ajuda técnica para a substituição da folha da coca por outros 
produtos agrícolas. 0 grande problema é que as vantagens oferecidas pelo governo não eram suficientes para compensar a perda da rentabilidade da terra com a mudança de produto cultivado, além da folha de coca ser um produto de consumo milenar dos povos indígenas (GOMES E SOUZA, 2009, p. 4).

Evo Morales, enquanto líder aymara do movimento cocalero boliviano, colocou-se peremptoriamente contra esse processo. No início de sua gestão presidencial, foi proibida a instalação de bases militares estrangeiras e a atuação dos agentes da $D E A$ no país e erradicado o modelo de combate ao narcotráfico imposto pelos Estados Unidos. Em contrapartida, implementou-se a política de "Cocaína Zero", centrada na erradicação da produção da droga no país, sem penalizar os povos indígenas e campesinos que a cultivam para fins religiosos, medicinais e mesmo sociais, conforme indica a Constituição:

\footnotetext{
El Estado protege a la coca originaria y ancestral como patrimonio cultural, recurso natural renovable de la biodiversidad de Bolivia, y como factor de cohesión social; en su estado natural no es estupefaciente. La revalorización, producción, comercialización e industrialización se regirá mediante la ley (art. 384).
}

Tais medidas provocaram retaliações por parte do governo dos Estados Unidos, que excluiu a Bolívia do rol de "beneficiários" da Ley de Preferencias Arancelarias Andinas y Erradicación de Drogas (ATPDEA, na sigla em inglês), acordo que prevê facilidades tarifárias para exportações de países andinos que se comprometam com a erradicação das drogas.

Outro breve atrito internacional no processo de autoafirmação da Bolívia sob a gestão Morales envolveu a política de nacionalização das reservas de hidrocarbonetos do país, que foi anunciada com a tomada simbólica da empresa petrolífera brasileira Petrobras pelas Forças Armadas bolivianas em maio de 2006. 0 abalo na relação diplomática entre Brasil e Bolívia, fortemente incentivados por setores oposicionistas dos governos de ambos os países, foi resolvido com um tratado que permitia gestão conjunta da Petrobras e da YPFB no processo de extração das reservas de gás natural bolivianas, auferindo uma maior porcentagem dos lucros à Bolívia (MAYORGA, 2007).

É importante notar que uma série de processos em curso no cenário internacional permitiram que a Bolívia concretizasse sua autoafirmação sob os novos princípios constitucionais sem graves consequências, passando para uma segunda fase de orientação da política externa pautada na busca por maior atuação, prestígio e relevância 
no cenário internacional. A crise sistêmica do capitalismo em 2008, com fortes repercussões nos Estados Unidos, levou o país norte-americano a focar sua atuação política na revitalização econômica interna, com um consequente breve período de diminuição nas ingerências e retaliações internacionais. Outro fator relevante é a ascensão econômica da China e aproximação desta dos mercados latino-americanos, que possibilitou à Bolívia uma alternativa comercial às retaliações inicialmente impostas pelos Estados Unidos.

Um terceiro elemento é a conjuntura regional no momento da chegada de Evo Morales ao poder, marcada pela ascensão de governos de esquerda e centro-esquerda em grande parte da América do Sul. Brasil, Argentina, Equador, Venezuela, Paraguai e Uruguai são países que no início do século XXI experimentaram esse processo. A afinidade ideológica entre os governos da região possibilitou, por exemplo, o não escalamento do atrito diplomático entre Brasil e Bolívia, novos acordos de cooperação econômica e a participação do Estado boliviano em novos mecanismos e alianças de integração regional.

É inclusive a partir da integração regional que a Bolívia começa a empregar recursos de Soft Power para promover um maior protagonismo nas relações internacionais. Inicialmente, a ideologia anti-imperialista e contestadora da ortodoxia neoliberal que orientou os processos de política doméstica e externa da Bolívia possibilitou o ingresso do país na Alianza Bolivariana para Nuestra América (ALBA) em 2006. A organização, à época composta por Cuba e Venezuela, consistiu em importante palco de cooperação comercial e social - principalmente nas áreas de saúde e educação no início do primeiro mandato presidencial de Evo Morales (GAITE, 2010).

A valorização boliviana da identidade andina, pressuposta em alguns dos princípios da Constituição de 2009, contribuiu para a eleição do país para a presidência pro tempore da Comunidade Andina (CAN) entre os anos de 2010 e 2011. Durante esse período, a Bolívia adotou uma agenda de busca por aprofundamento da integração econômica e política da região e redução de assimetrias entre os Estados-membros, procurando revitalizar a instituição.

A condução da política externa comprometida com a concretização da integração latino-americana em todos os âmbitos possíveis, bem como o sucesso das políticas públicas domésticas, refletido no aumento dos índices de crescimento econômico e desenvolvimento social, possibilitaram à Bolívia a ascensão para um maior protagonismo 
em instituições regionais de escopo maior. A cidade boliviana de Cochabamba foi escolhida para sediar o Parlamento Sul-Americano, instância legislativa da UNASUL. Em 2012, o país sediou a 42 ${ }^{\mathrm{a}}$ Assembleia Geral da Organização dos Estados Americanos (OEA), marcada por fortes discursos de lideranças regionais contrárias às relações de hegemonia e tutela dos Estados Unidos para com os demais países da organização. No mesmo ano, foi assinado o Tratado de Adesão do Estado Plurinacional da Bolívia ao Mercosul, que atualmente aguarda a ratificação de todos os países-membros para entrar em vigor.

A utilização de valores culturais e princípios ideológicos positivados na Constituição de 2009, bem como do prestígio das políticas domésticas e de uma inserção internacional cada vez mais proativa no cenário regional, pautou também a procura da Bolívia por um maior protagonismo nas demais instâncias da comunidade internacional. Nesse segundo momento das relações exteriores da Bolívia sob a gestão Morales, houve a diminuição no radicalismo dos aspectos discursivos anti-imperialistas e contestadores da hegemonia estadunidense. No lugar desses fundamentos, a Bolívia buscou uma inserção consonante com princípios universais em evidência na agenda internacional, tais como os direitos humanos, a preservação do meio ambiente, emancipação indígena, equidade e justiça no Direito Internacional e autodeterminação dos povos.

De maneira independente, o governo boliviano promoveu em 2010 a Primeira Conferência Mundial dos Povos sobre as Mudanças Climáticas e os Direitos da Mãe Terra, propondo o debate acerca do tema e estabelecimento da Natureza enquanto sujeito de Direito Internacional, visando a sua proteção. Apesar da ampla visibilidade e participação da comunidade internacional, poucos resultados concretos resultaram da iniciativa do país.

No âmbito da Organização das Nações Unidas (ONU), a Bolívia exerceu papel central no processo de aprovação pela Assembleia Geral da Declaração Universal dos Direitos dos Povos Indígenas, em 2007, e tem liderado no seio da organização a luta contra a criminalização do cultivo tradicional e medicinal da folha de coca em seu estado natural. Ainda nas Nações Unidas, houve recentemente a tentativa de exercer protagonismo na concretização das Metas de Desenvolvimento do Milênio, em especial a erradicação da fome. Nesse processo, outro elemento típico da cultura indígena tradicional boliviana foi utilizado: a quinua, grão de alto valor nutricional cultivado há milênios pelos povos 
originários dos Andes, promovido pela Bolívia como "superalimento" com forte potencial para a solução da fome mundial. Como resultado, 2014 foi consagrado pela Assembleia Geral da ONU como Ano Internacional da Quinua, e Evo Morales recebeu o extravagante título de "Embaixador da Quinua no Mundo" pela Organização das Nações Unidas para a Alimentação e Agricultura (FAO).

São processos como esses, muitas vezes mais simbólicos que concretos, que marcam o estilo que o Estado Plurinacional da Bolívia, sob a gestão Morales, tem utilizado para superar suas limitações militares e econômicas e pautar uma inserção assertiva no cenário internacional.

\section{Considerações Finais}

A partir da perspectiva analítica pluralista adotada nesse artigo, pode-se notar que a drástica alteração na correlação de forças no interior da arena doméstica do Estado Plurinacional da Bolívia repercutiu em uma série de mudanças na política externa do país. Enquanto outrora havia o predomínio de elites agroexportadoras e agroindustriais, defensoras de um projeto de inserção internacional subserviente às dinâmicas do capital internacional, a chegada de Evo Morales e do Movimiento al Socialismo ao poder, com amplo apoio da população e dos movimentos sociais, possibilitou o início da implementação de uma política externa "própria e propositiva" (MRE, 2014), buscando maior autonomia e protagonismo nos processos internacionais.

Nesse processo, a consolidação constitucional dos princípios e valores que compõem o Vivir Bien tiveram importância fundamental. A consonância com valores culturais aceitos como universais (emancipação indígena, proteção do meio ambiente, autodeterminação dos povos) e consolidação de políticas públicas domésticas bemsucedidas (redistribuição de riqueza através de programas sociais, com aumento exponencial nos índices de crescimento econômico e desenvolvimento social) consistiram em importantes recursos de Soft Power boliviano, permitindo ao país uma superação das limitações materiais (baixa capacidade militar e parcos recursos econômicos) ao exercício de poder.

Assim, o país tem logrado a concretização de dupla agenda em sua política exterior: 
o sucesso das políticas públicas domésticas e os princípios contestadores da ordem neoliberal permitem ao país participação crescente em mecanismos anti-hegemônicos de integração regional. Ao mesmo tempo, valores centrais da cultura política e legislação interna da Bolívia - principalmente relacionados a questões indígenas e ambientais - são utilizados na busca por legitimidade, prestígio e manutenção de certo grau de relevância do país junto à comunidade internacional.

\section{REFERÊNCIAS}

ACOSTA, Alberto. El Buen Vivir en el camino del post-desarrollo Una lectura desde la Constitución de Montecristi. Policy Paper, n. 9. 2010. Disponível em: < https://www.fuhem.es/media/cdv/file/biblioteca/Analisis/Buen_vivir/Buen_vivir_pos desarrollo_A._Acosta.pdf>. Acesso em: 23 de junho de 2015.

ARZE, Carlos Vargas. Las rebeliones populares de 2003 y la demanda de nacionalización de los hidrocarburos: Fin de la era neoliberal en Bolivia?. Cuadernos del Cendes, 2004. Disponível em: <http://cendes-ucv.edu.ve/pdfs/56Cuadernos\%2038-104.pdf>. Acesso em 30 de Junho de 2015.

BOLÍVIA. Constituição (2009). Constitución Política del Estado Plurinacional de Bolívia. La Paz, Bolívia. 178 p. Disponível em: <http://www.harmonywithnatureun.org/content/documents/159Bolivia\%20Consituci on.pdf>. Acesso em 22 de junho de 2015.

Ministerio de Relaciones Exteriores y Culto. La Revolución Democrática y

Cultural y su Política Exterior. Memoria 2006 - 2013. La Paz, Bolívia. 2014. Disponível em: < http://www.consuladodebolivia.ch/index.php/es/noticias-actuales/item/43politica-exterior/43-politica-exterior>. Acesso em 28 de agosto de 2015.

BURCKHART, Thiago Rafael. O "Novo" Constitucionalismo Latino-Americano e a Positivação de Direitos Pluralistas: Uma Análise Crítica do Direito Indígena. Revista Direito e Política, v. 8, n. 2, p. 1005-1022, 2013.

FERNÁNDEZ, Hugo. Suma Qamaña, Vivir Bien, el Ethos de la Nueva Constitución Boliviana. Revista Obets, n. 4, 2009. pp. 41-48. Disponível em: < 
http://rua.ua.es/dspace/handle/10045/13381>. Acesso em 16 de agosto de 2015.

FIGUEIRA, Ariane Roder. Introdução à análise de política externa. v. 1, São Paulo: Saraiva, 2011.

GAITE, Alberto Solares. Integración: Teoría y Procesos. Bolívia y la Integración. La Paz, Bolívia, 2010. Disponível em: <http://www.eumed.net/librosgratis/2010e/814/indice.htm>. Acesso em 07 de setembro de 2015.

GOMES E SOUZA, J. Crise do neoliberalismo e seus reflexos no aparelho estatal: apontamentos para a reflexão do caso boliviano. In: VI Colóquio Marx Engels, 2009, Campinas. Anais, 2009.

HERNÁNDEZ, Maribel. Sumak Kawasay y Suma Qamaña, el reto de aprender del sur. Reflexiones en torno al Buen Vivir. Revista Obets, n. 4, 2009. pp. 57-67. Disponível em: < http://rua.ua.es/dspace/handle/10045/13381>. Acesso em 16 de agosto de 2015.

LIMA, Marina Regina Soares de. Instituições Democráticas e Política Exterior. Revista Contexto Internacional, Rio de Janeiro, v. 22, n.2, 2007. Disponível em: < http://contextointernacional.iri.puc-rio.br/media/Lima_vol22n2.pdf>. Acesso em 07 de setembro de 2015.

LOPES, Dawisson Belém. Democratic foreign policy: oxymoron, chimera, or trend?. Revista Brasileira de Ciências Sociais, v. 27, n. 80, p. 185-202, 2012.

MAYORGA, Fernando. El Gobierno de Evo Morales: Cambios Políticos y Transición Estatal en Bolívia. Centro de Estudos Superiores Universitários, 2007. Disponível em: < http://www.pieb.com.bo/blogs/mayorga/archivos/Articulo_mayorga.pdf>. Acesso em: 28 de junho de 2015.

MENEZES, Wagner. Direito Internacional Público na América Latina. 22. ed. Curitiba: Juruá, 2007. 320p.

MINGST, Karen. Princípios de relações internacionais. Elsevier Brasil, 2009.

NYE, Joseph S. Soft Power: The Means to Success in World Politics. New York: Public Affairs, 2004. 
QUIJANO, Aníbal. Colonialidade do poder, eurocentrismo e América Latina. In: LANDER, Edgardo. (Org.). A colonialidade do saber: eurocentrismo e ciências sociais. Perspectivas latinoamericanas. Colección Sur Sur, CLACSO, Ciudad Autonoma de Buenos Aires, Argentina. 2005. pp. 107 - 130.

SARFATI, Gilberto. Teorias de relações internacionais. Editora Saraiva, 2005.

TAPIA, Luis. Una Relfexión sobre la Idea de Estado Plurinacional. Debates. Ano VII, v. 22, 2007. Disponível em:

http://bibliotecavirtual.clacso.org.ar/ar/libros/osal/osal22/D22Tapia.pdf>. Acesso em: 30 de junho de 2015.

TORTOSA, 2009. Maldesarollo: entre el "American Way of Life" y el "Sumak Kawsai". Instituto Universitario de Desarollo Social y Paz, 2009. Disponível em: <https://sumakkawsay.files.wordpress.com/2009/06/tortosa_maldesarrollo_sk.pdf>. Acesso em 22 de junho de 2015.

ZUAZO, Moira. ¿Los movimientos sociales en el poder? El gobierno del MAS en Bolivia. Revista Nueva Sociedad, Buenos Aires, n. 227, pp. 120-135 n. 227, 2010. Disponível em:

http://www.plataformademocratica.org/Publicacoes/22804_Cached.pdf>. Acesso em: 24 de agosto de 2015. 